\title{
Lise Öğrencilerinin İngilizce Özerklik Algısı, Kaygısı ve Özyeterlik İnancı Arasındaki İlişkinin İncelenmesi
}

\author{
DOI: $10.26466 /$ opus.537460 \\ * \\ Șenol Orakc1 $^{*}$ - Osman Aktan** - Çetin Toraman*** \\ * Dr Öğr. Üyesi, Aksaray Üniversitesi, Eğitim Fakültesi, Merkez/ Aksaray/ Türkiye \\ E-Posta: senolorak@gmail.com ORCID: 0000-0003-1534-1310 \\ **Dr., Milli Eğitim Bakanlığı, Merkez / Düzce / Türkiye \\ E-Posta: karakteregitimi@gmail.com \\ ORCID: $\underline{0000-0001-6583-3765}$ \\ *** Dr Öğr. Üyesi, Çanakkale Onsekiz Mart Üni. Tıp Fak., Çanakkale/Türkiye \\ E-Posta: cetintoraman@gmail.com \\ ORCID: 0000-0001-5319-0731
}

\section{Öz}

Bu araştırmada, lise öğrencilerinin İngilizce özyeterlik algıları, kaygı düzeyleri ile özerklik algıları arasındaki ilişkinin ve İngilizce kaygı düzeyinin özyeterlik aracı değgiskeni üzerinden özerklik üzerindeki etkisini incelemek amaçlanmaktadır. Araştırmada lise öğrencilerinin İngilizce öz yeterlik düzeyi aracı değişkeni üzerinden Ingilizce kaygı düzeyinin özerklik üzerindeki açıklayıcllı düzeyi ve bu değişkenler arası ilişkiler incelenmiştir. Araştırma ilişkisel karşılaştırma türünde bir araştırmadır. Araştırmada veri toplama aracı olarak "İngilizce ile İlgili Özyeterlik İnancı Ölçeği", "Özerklik Alg̨ Ölçeği" ve "Yabancı Dil Öğrenme Kaygısı Ölçeği" olmak üzere üç farklı ölçek kullanılmıştır. Araştırmada örneklem belirlenirken kolay ulaşılabilirlik esası gözetildiği için "amaçlı örneklem yöntemi" benimsenmiş olup araştırmanın örneklemini toplam 645 lise 10. sinı öğrencisi oluşturmaktadır. Araştırma bulguları, İngilizce özyeterlik inancı ile özerklik algısı, İngilizce özyeterlik inancı ile yabancı dil öğrenme kaygısı, özerklik algısı ile yabancı dil öğrenme kaygısı arasında ilişkiler olduğunu göstermektedir. Bu bağlamda araştırma sonuçları İngilizce özyeterlik algıları, kaygı düzeyleri ile özerklik algıları ile yapılan diğer araştırma sonuçları ile ilişkilendirilerek tartışılmıştır.

Anahtar Kelimeler: Yabancı dil eğitimi, Özerklik, Özyeterlik, Kaygı 


\title{
An Investigation of the Relationships Between English Language Learning Autonomy Perception, Anxiety Level and Self-Efficacy Perception among High School Students
}

\begin{abstract}
The study aims to investigate the relationships between English language learning autonomy perception, anxiety level and self-efficacy perception among high school students and whether foreign language learning anxiety level and self-efficacy perception predict students' English language learning autonomy perception significantly. The relational screening model was used in the research. In the study, three different scales, "Self-Efficacy Belief Scale for English", "Autonomy Perception Scale" and "Foreign Language Learning Anxiety Scale" were used as data collection tools. In the study, "purposive sampling method" was adopted taking into account that the sampling was easy to reach and the sample of the study consisted of 645 high school 10th grade students. With regard to the findings of the study, it was found out that there were relationships between self-efficacy and autonomy perception, between self-efficacy and foreign language learning anxiety anxiety and between foreign language learning anxiety and autonomy perception in English learning. In this context, the results of the study were discussed with the other study results about learning autonomy perception, anxiety level and self-efficacy perception
\end{abstract}

Keywords: Foreign language education, Autonomy, Self-efficacy, Anxiety 


\section{Giriş}

İçinde yaşadığımız yüzyılda bilgi ve teknoloji alanında yaşana gelişmelere bağlı olarak, artan kitle iletişim araçları kişi ve toplumların daha fazla iletişim ve etkileşim içinde olmalarına yol açmıştır. Kişi ve toplumlar arası etkileşimin sağlanmasında yabancı dil önemli bir yere sahiptir (Demirel, 2014). Yabancı dil öğrenmek farklı kültürleri tanımayı, farklı alanlarda elde edilmiş bilgi birikimine ulaşmayı ve evrensel düşünmeyi sağlar. Aynı zamanda dil öğrenme, yeni iş imkânlarının oluşması, farklı düşünce ve anlayışları kavrama konusunda fırsatlar sunar (Bahar, 2011; İşcan, 2011). Yabancı dil öğrenmek, sorunların çözümünde bireylere çözüm için geniş bir bakış açısı ile sorunlara yönelik özgün çözüm stratejileri ve yaratıcılık becerileri geliştirmelerini sağlar (Ghonsooly ve Showqi, 2012; Hommel, Colzato, Fischer ve Christoffels, 2011; Pop, 2011). Yabancı dil öğrenmek, zihinsel gelişim olarak insanı bulunduğu yerden daha bir üst noktaya taşır (Connor, 2016; König, 1989).

Yabancı dili etkili kullanabilmek için dilin kendi yazılı ve sözlü biçimini kullanmak, anlamak ve geliştirmek gerekmektedir (Kupeckova, 2010, 15). Bununla birlikte yabancı dil öğreniminde tutum ve inançlar, motivasyon, öğrenme sitilleri, öğretim stratejileri, kişilik, dil yeteneği, özyeterlik, öğrenen özerkliği, kaygı gibi çeşitli bilişsel ve duyuşsal özellikler etkili olmaktadır. (Cook, 2008; Dörnyei, 2005; Dörnyei, 2012; Little, 1999; Little, 2000; Roberts ve Meyer, 2012; Skehan,1989). Bu özellikler dil öğrenmede avantaj sağladığı gibi zorlukların da ortaya çıkmasına neden olabilmektedir.

Yabancı bir dil öğrenmek kendi içinde belli zorluklar taşımaktadır (Kupeckova, 2010, s.15). Bu zorlu süreçte dil öğreniminde başarı için kişinin kendi öğrenmelerinde sorumluluk almasına dayalı olan ve yabancı dil öğreniminde bir amaç ve araç olarak kabul edilen öğrenen özerkliği etkili unsurların başında gelmektedir (Benson, 2007; Little, 2007). Öğrenen özerkliği; öğrencilerin öğrenmenin amaç ve içeriği üzerinde kontrol sahibi olmaları (Holec, 1983; Little, 1991) öğrenmenin sorumluluğunu üstelenme yeteneği (Holec, 1981; Benson ve Voller, 1997), kişisel dil farkındalığı oluşturma (Lier,1996), kendi öğrenmeleri ile ilgili kararlar alma ve uygulama (Holec, 1985; Dickinson, 1995) şeklinde özetlenebilir. Özerkliğin, 
öğrenim durumlarından ziyade, öğrencilerin öğrenmeye yönelik sahip olduğu kişisel yeterlilikler olduğu söylenebilir (Dickinson, 1987).

Öğrenme özerkliği dil edinimi için önemli bir rol oynar (Khojasteh ve Pishkar, 2015). Dil öğrenmede özerklik; bireysel katılım, eleştirel yansıtma, karar verme ve bağımsız olarak uygulamaya geçme becerilerine dayanır (Little, 1991). Son yıllarda dil öğretiminde, öğrencilerin başarılı olabilmek için sadece sınıfta değil, aynı zamanda sınıf dışında da bir denetim etmeni olmadan kendi öğrenmelerini kontrol edebilmeleri düşüncesi yaygın kabul görmeye başlamıştır (Benson, 2006; Gremmo ve Riley, 1995). Öğrenen özerkliği yeni bir dil öğrenmede etkili olduğu gibi, bireysel öğrenme becerilerinin de gelişmesini sağlar (Orakc1, 2017; Orakcı ve Gelişli, 2017). Öğrencinin özerk davranabilmesini sağlayan en temel unsurlardan bir tanesi öğretmenin öğrenciye yaklaşım tarzıdır (Göçer, 2016). Dil eğitiminde görev alan öğretmenler, dil öğrenmede öğrencilerin bireysel olarak öğrenme ve öğrenmede sorumluluk alma becerilerini geliştirmek amacıyla öğrenen merkezli öğrenme ortamlarına daha fazla yer vermelidirler (Çakıcı, 2015; Nunan, 2004). Bununla birlikte öğrencilerin daha fazla bağımsız olarak öğrenmelerini sağlamak amacıyla, özerkliğin kabul gördüğü bir sınıf kültürü oluşturulması, öğrencilerin motivasyon, güven, bilgi ve öz-yeterlilik becerilerini geliştirmelerine yardımcı olacak danışman, analizci, gözlemci, kolaylaştırıcı özerklik rolleri üstlenmeleri gerekli görülmektedir (Camilleri, 1997; Scharle ve Szabo, 2000; Şanal, 2016). Alg1lanan özerklik desteği gibi algılanan özyeterlik inancı da öğrencilerin performanslarını etkileyen önemli etkenlerden biridir (Bandura, 1977).

Özyeterlik inancı, kişinin belli bir performansı gösterebilmesine yönelik kendi kapasitesine ilişkin kişisel yargısını ifade etmektedir (Bandura, 1997). Öz yeterlik inançları bireyin bir etkinliği seçmesini, etkinlikte gösterdiği ısrar ve çaba ile başarısını doğrudan etkilemektedir (Shunk, 2003). Kendi anadilinden farklı bir dili öğrenmede kişinin kendi dil öğrenme yeteneğine ilişkin inanç ve tutumunun olumsuz olduğu durumlarda kayg1 gündeme gelmektedir.

Genel olarak kayg1, korku, endişe, sıkıntı, belirsizlik, huzursuzluk ve hoş olmayan duygu durumlarını ifade ederken (Sapir ve Aranson, 1990); yabancı dil öğrenme kaygısı, bireyin anadili olmayan bir dili öğrenirken veya günlük hayatta kullanırken hissettiği korku ve endişelerini kapsar (Gregersen ve Horwitz, 2002; Horwitz, 2001; MacIntyre ve Gardner, 1989). 
Öğrenende ortaya çıkan kaygı durumunun yabancı dil ile ilgili kazanımlara ulaşma ve dil yeterliliği önünde engel olduğu araştırmalarla ortaya konulmuştur (Ganschow ve Sparks, 1996; Horwitz, Horwitz, ve Cope, 1986; Horwitz ve Young, 1991; Macintyre, 1995). İkinci dil öğreniminde kaygı, dil öğrenme sürecini zor ve stresli bir hale dönüştürebilmektedir (Gass ve Selinker, 2008). Anadillerinde kendilerini başarı ile ifade eden bireyler, yabancı bir dilde kendini ifade etmekte zorlanmakta ve yabanc1 dile yönelik özyeterlik inançları yerini, çekingenlik, korku, özgüven kaybı hatta ve paniğe bırakabilmektedir (Horwitz, Horwitz, ve Cope, 1986). Bunun aksine yapılan bazı araştırmalarda ise kaygının dil öğrenme başarısı üzerinde olumlu etkisi olduğu belirlenmiştir (Bailey, 1983; Brown, 2000). Öğrencilerde yabancı dil öğrenme kaygısını azaltmak için, öğrencilerin yabancı dil öğrenme gerekliliğine olan inanç ve tutumlarını olumlu yönde desteklemek, öğrencilerin ilgi, dikkat ve motivasyonlarını canlı tutmak adına dil öğretiminde konu odaklı farklı yöntem ve tekniklere yer vermek, öğrenme ortamını eğlenceli hale getirmek gerekir.

Yurtiçi ve yurt dışında yapılan araştırmalar incelendiğinde son yıllarda İngilizce eğitiminde özyeterlik inancı, kaygı ve özerklik algıları ile ilgili çalışmaların artmaya başladığı söylenebilir. Yapılan çalışmalar incelendiğinde; öğrencilerin İngilizce ile ilgili özyeterlik inançları (Blumenthal, 2014; Yanar ve Bümen, 2012; Raoofi, Tan, ve Chen, 2012; Yanar ve Bümen, 2012), özyeterlik inancı ile özerklik arasında ilişki (Kanadlı ve Bağçeci, 2015; Orawiwatnakul ve Wichadee, 2017; Tilfarlioğlu ve Çiftci, 2011), dil öğrenmede kaygı (Baş, 2013; Orakc1, 2018), dil öğrenmede kaygı ve akademik başarı (Amiri ve Ghonsooly, 2015; Amiri ve Ghonsooly, 2015: Chen ve Chang, 2009; Dordinejad ve Ahmadabad, 2014; Horwitz, 2001; Liu, 2006; MacIntyre ve Gardner, 1994), dil öğrenme kaygısı ve motivasyon (Gardner, Lalonde, Moorcroft, ve Evers 1987; Hashimoto, 2002; Liu,2012; Tahernezhad, Behjat, ve Kargar, 2014), yabancı dil öğrenme kaygısı ile özyeterlik arasındaki ilişki (Anaydubalu, 2010; Aydın, 2016; Bensalem, 2018; Coşkun, 2017; Çimen, 2011; Çubukçu, 2008; Demir, 2018; Ghonsooly ve Elahi, 2010; Oğuz ve Baysal, 2015; Tuncer ve Doğan, 2015; Tuncer ve Doğan, 2016), öğrencilerin İngilizce ile ilgili özerklik algıları (Bayat, 2007; Yiğit ve Yıldırım, 2018) özerklik algısı ve yabancı dil öğrenme kaygısı arasindaki ilişki (Dordinejad ve Ahmadabad, 2014; Kurt, 2016; Liu, 2012; Sa- 
nadgol ve Abdolmanafi-Rokni, 2015), yabancı dil eğitiminde özerkliği teşvik etme (Liu, 2015; Mede, İnceçay, ve İnceçay, 2013; Sakai, Takagi, ve Chu, 2010) konularında çalışmalar yapıldığı görülmektedir.

Yabancı dil derslerinde kaygı düzeyi, öğrenen özerkliği ve öz-yeterlik algıları, yabancı dil öğrenmede öğrencilerin performanslarını etkileyebilen önemli değişkenler olabilir. Yapılan çalışmalarda lise öğrencilerinin İngilizce kaygı düzeyinin özyeterlik aracı değişkeni üzerinden özerklik üzerindeki etkisi ile İngilizce özyeterlik algıları, kaygı düzeyleri ve özerklik algıları arasındaki ilişkilerin incelenmesine yönelik herhangi bir araştırmaya rastlanılmamış olması bu araştırmayı önemli ve özgün kılmış olup yapılan çalışmanın alanyazına önemli katkı sağlayacağı inanılmaktadır. Bu araştırmanın amacı lise öğrencilerinin İngilizce özyeterlik alg1ları, kaygı düzeyleri ve özerklik algıları arasındaki ilişkinin ve İngilizce kaygı düzeyinin özyeterlik aracı değişkeni üzerinden özerklik üzerindeki etkisini incelemektir.

\section{Yöntem}

Araştırmada lise öğrencilerinin İngilizce öz yeterlik düzeyi aracı değişkeni üzerinden İngilizce kaygı düzeyinin özerklik üzerindeki açıklayıcılık (exploratory/predicting) düzeyi ve bu değişkenler arası ilişkiler incelenmiştir. Araştırma bu yönüyle ilişkisel karşılaştırma türünde bir araştırmadır (Fraenkel, Wallen, ve Hyun, 2012).

\section{Çalışma Grubu}

Araştırmaya Ankara ilinde yer alan beş merkez ilçenin (Altındağ, Çankaya, Keçiören, Mamak ve Yenimahalle) her birinden birer lisesi (öğrenci sayısı bakımından büyük okullar) olmak üzere toplam 5 farklı liseden 645 lise 10. sınıf öğrencisidir. Bu öğrencilerin 341'1 (\%53) kadın ve 304'ü (\%47) erkektir. Örneklem belirlenirken kolay ulaşılabilirlik, araştırmaya katılımda gönüllülük esasları gözetildiği için "amaçlı örneklem yöntemi" benimsenmiştir. Amaçlı örnekleme kitlenin tümü değil bir kısmı ile çalışılması esasıyla oluşturulur (Şenol, 2012). Amaçlı örneklem kullanılırken araştırmacılar, araştırma evreni oluşturacak kişilerin özelliklerini belirler ve bu özelliklere uyan kişilere ulaşır (Christensen, Johnson, ve Turner, 
2014). Bu araştırmada onuncu sınıfların seçilme gerekçesi şöyle açıklanabilir. Ortaöğretim dört yıllık bir eğitimdir. Dokuzuncu sınıflar ortaöğretime yeni başlamıştır ve okula uyum süreçleri devam etmektedir. On bir ve on ikinci sınıflar ise üniversite giriş sınavına hazırlanmaktadır ve sınav kaygısı yaşamaktadır çoğunlukla. Bu nedenle en uygun sınıfın onuncu sinıf olduğu düşünülmüştür.

\section{Veri Toplama Araçları}

Bu araştırmada "İngilizce ile İlgili Özyeterlik İnancı Ölçeği (İïÖIÖ)", “Özerklik Algı Ölçeği (ÖAÖ)” ve "Yabancı Dil Öğrenme Kaygısı Ölçeği (YDÖKÖ)" veri toplama araçları olarak kullanılmıştır.

İngilizce ile İlgili Özyeterlik İnancı Ölçeği (İIÖİÖ): Hancı Yanar ve Bümen (2012) tarafından geliştirilmiştir. Ölçek lise öğrencilerinin İngilizce ile ilgili özyeterlik inançlarının belirlenmesi amacıyla geliştirilmiştir. Ölçekte 5 dereceli cevaplama yapısına sahip 34 madde yer almaktadır. Ölçek dört alt boyuttan oluşmaktadır. Bunlar: 1) okuma, 2) yazma, 3) dinleme ve 4) konuşmadır. Ölçekten en yüksek 170 puan alınabilmekteyken, en düşük ise 34 puan alınabilmekdir. Yüksek puan yüksek özyeterlik inancına sahip olma derecesi şeklinde yorumlanmaktadır. Ölçeği geliştiren araştırmac1lar veriler üzerinden doğrulayıcı faktör analizi (DFA) (confirmatory factor anaylsis [CFA]) uygulanmıştır. DFA sonuçlarında elde edilen uyum indeksleri "RMSEA=0.044", "NNFI=0.99", “CFI=0.99", “NFI=0.98”, "PNFI=0.89", “IFI=0.99", “RFI=0.98" olarak belirlenmiştir. Elde edilen değerler alanyazına göre kabul edilebilir değerlerdir (Özdamar, 2013; Şimşek, 2007; Sümer, 2000). Ölçeği geliştirenler tarafından ölçeğin tümüi için Cronbach Alpha güvenirlik değeri 0.97 olarak hesaplanmıştır. Bu araştırma kapsamında toplanan verilere Cronbach Alpha güvenirlik katsayısı hesaplanmıştır. Güvenirlik değeri 0,89 olarak belirlenmiştir.

Özerklik Algı Ölçeği (ÖAÖ): Bayat (2007) tarafından geliştirilmiştir. Bayat (2007) ölçeği lisans öğrencileri üzerinden geliştirmiştir. Kurt (2016) aynı ölçeği lise öğrencileri üzerinde kullanmıştır. Ölçekte 5 dereceli (tamamen katılıyorum, katılıyorum, kararsızım, katılmıyorum, hiç katılmıyorum) 
cevaplama yapısına sahip 38 madde yer almaktadır. Ölçek dört alt boyuttan oluşmaktadır. Bunlar: "1) dil öğrenme sorumluluğunu üzerine alma, 2) okul dışı İngilizce etkinliklerini yürütme, 3) bilişüstü strateji kullanma ve 4) gerçek hayatta öğrenilen dili ilişkilendirme"dir. Ölçekten en yüksek 190 puan alınabilmekteyken, en düşük ise 38 puan alınabilmekdir. Yüksek puan yüksek özerklik algısı anlamında yorumlanmaktadır. Ölçeğin tümü için Cronbach Alpha güvenirlik değeri 0.90 olarak hesaplanmıştır. Kurt'un (2016) ölçeğinde lise öğrencileri üzerinde kullanmak için Cronbach Alpha güvenirlik katsayısı 0.90 olarak hesaplanmıştır. Bu araştırma kapsamında ise toplanan veriler için Cronbach Alpha güvenirlik katsayısı 0,92 olarak belirlenmiştir.

Yabancı Dil Öğrenme Kaygısı Ölçeği (YDÖKÖ): Baş (2013) tarafından geliştirilmiştir. Ölçek ortaokul (6, 7 ve 8. sınıf) öğrencilerinin yabancı dil öğrenme kaygısının belirlenmesi amacıyla geliştirilmiştir. Ölçekte 5 dereceli (kesinlikle katılıyorum, katılıyorum, kararsızım, katılmıyorum, kesinlikle katılmıyorum) cevaplama yapısına sahip 27 madde yer almaktadır. Ölçek üç alt boyuttan oluşmaktadır. Bunlar: "1) kişilik, 2) iletişim ve 3) değerlendirme" dir. Ölçekten en yüksek 135 puan alınabilmekteyken, en düşük ise 27 puan alınabilmekdir. Yüksek puan yüksek özyeterlik inancına sahip olma derecesi şeklinde yorumlanmaktadır. Ölçeğin tümü için Cronbach Alpha güvenirlik değeri 0.93 olarak hesaplanmıştır. Bu araştırmada ölçek lise öğrencilerine uygulanmıştır. Yapılan uygulama sonucunda Cronbach Alpha güvenirlik katsayısı 0.89 olarak hesaplanmıştır. Bu araştırma kapsamında toplanan verilere Cronbach Alpha güvenirlik katsayısı hesaplanmıştır. Güvenirlik değeri 0,82 olarak belirlenmiştir.

\section{Verilerin Analizi}

Araştırma amacı doğrultusunda veri analizinde; ilişki analizleri ve yol (path) analizi uygulaması gerekmektedir. Elde edilen verilerin normal dağılım göstermesi ilişki analizinde "Pearson Momentler Çarpımı Korelasyon Katsayısının" ve değişkenler arası etkilerin incelenmesi için ise "Yol (Path) Analizinin" kullanılabilmesine olanak vermektedir. Veriler normal dağılmadığı takdirde ilişki analizinin "Spearman Brown Sıra Farkları Ko- 
relasyon Katsayısı" ile hesaplanması gerekmektedir. Bu gerekçelerle "İngilizce ile İlgili Özyeterlik İnanc Ölçeği (İIÖIÖ)”, "Özerklik Alg1 Ölçeği (ÖAÖ)" ve "Yabancı Dil Öğrenme Kaygısı Ölçeği (YDÖKÖ)" puanlarına "Kolmogorov-Smirnov Normal Dağılım Testi" (Büyuiköztürk, 2013; Kalayc1, 2005; Green ve Salkind, 2008; Özdamar, 2013) uygulanmıştır.

645 öğrenci üzerinden elde edilen verilere ait Kolmogorov-Smirnov Normal Dağılım Testi sonuçları tablo 1'de verilmiştir.

Tablo 1. Normal dağılım testi sonuçları $(n=645)$

\begin{tabular}{lc}
\hline Değişken & $\mathbf{p}$ \\
\hline İngilizce Özyeterlik İnancı & 0.200 \\
Özerlik Alg1sı & 0.200 \\
Yabancı Dil Öğrenme Kaygısı & 0.077 \\
\hline
\end{tabular}

Tablo 1'de görüldüğü gibi uç veri ayıklamasından sonra kalan verilerde normal dağılım sağlanmıştır. Tek değişkenli olarak incelenen normal dağılım çok değişkenli normal dağılım varsayımı altında da incelenmiştir. Elde edilen verilerin çok değişkenli normal dağılım gösterip göstermediğinin incelenmesi için veriler istatistik paket programına aktarılmıştır. Çok değişkenli normal dağılım incelemesi, "Doornik-Hansen Test" aracılığıyla STATA programında yapılabilmektedir (STATA, 2013). Test sonuçları tablo 2'de özetlenmiştir.

Tablo 2. Doornik-Hansen çok değişkenli normal dă̆ılım testi sonuçları

\begin{tabular}{lcc}
\hline Değişkenler & $X^{2}$ & $\mathbf{p}$ \\
\hline $\begin{array}{l}\text { İngilizce Özyeterlik İnancº̈zerklik Algısı*Yabancı Dil Öğ- } \\
\text { renme Kaygisı }\end{array}$ & 8,12 & 0.10 \\
\hline
\end{tabular}

Tablo 2 incelendiğinde üç ayrı ölçeğin puanlarının çok değişkenli normal dağılım gösterdiği $(\mathrm{p}<.05)$ anlaşılmıştır. Elde edilen bu sonuçlar doğrultusunda ilişki analizlerinin "Pearson Momentler Çarpımı Korelasyon Katsayısı" ile yapılmasına ve yol analizi modelinin kurulmasına karar verilmiştir. 


\section{Bulgular}

İngilizce Özyeterlik İnancı, Özerklik Algısı, Yabancı Dil Öğrenme Kaygisı İlişkisi

Lise öğrencilerinin algıladıkları özerklik düzeyi, İngilizce özyeterlik inanç düzeyi ve yabancı dil öğrenme kaygısı düzeyi arasındaki ilişkiler incelenmiştir. Buna yönelik sonuçlar tablo 3'te verilmiştir.

Tablo 3. Özerklik, özyeterlik ve kaygı düzeyi ilişkisi

\begin{tabular}{|c|c|c|c|}
\hline & $\begin{array}{l}\text { İngilizce Özyeterlik } \\
\text { Ínancı }\end{array}$ & $\begin{array}{l}\text { Özerklik } \\
\text { Algısı }\end{array}$ & $\begin{array}{l}\text { Yabancı Dil Öğrenme } \\
\text { Kaygısı }\end{array}$ \\
\hline \multicolumn{4}{|c|}{ İngilizce Özyeterlik } \\
\hline İnanc1 & - & & \\
\hline Özerklik Algısı &, $89^{* *}$ & - & \\
\hline \multicolumn{4}{|c|}{ Yabancı Dil Öğrenme } \\
\hline Kayg1sı &, $83^{* *}$ &,$- 73^{* *}$ & - \\
\hline
\end{tabular}

Tablo 3'te görüldüğü gibi İngilizce özyeterlik inancının özerklik algısı ile pozitif yönde, yüksek düzeyde anlamlı ilişki gösterdiği $(\mathrm{p}<.05)$ belirlenmiştir. İngilizce özyeterlik inancının yabancı dil öğrenme kaygısı ile negatif yönde, yüksek düzeyde ve anlamlı ilişki gösterdiği $(\mathrm{p}<.05)$ belirlenmiştir. Özerklik algısı ile yabancı dil öğrenme kaygısının negatif yönde, yüksek düzeyde ve anlamlı ilişkili olduğu $(\mathrm{p}<.05)$ belirlenmiştir. Yabancı dil kaygı düzeyi arttıkça İngilizce özyeterlik inancı ve özerklik algısı düşmektedir. Buna karşın özerklik algısı arttıkça İngilizce özyeterlik inancı da artmaktadir.

\section{İngilizce Özyeterlik İnancı Aracı (Mediator) Değişkeninde, Yabancı Dil Öğrenme Kaygisının Özerkliğe Etkisi}

Lise öğrencilerinin İngilizce özyeterlik inançları aracı değişken olarak alındığında yabancı dil öğrenme kaygısının özerkliğe etkisi incelenmiştir. $\mathrm{Bu}$ inceleme yol (path) analizi ile yapılmıştır. Yol analizine ilişkin diyagram şekil 1'de görülmektedir. 


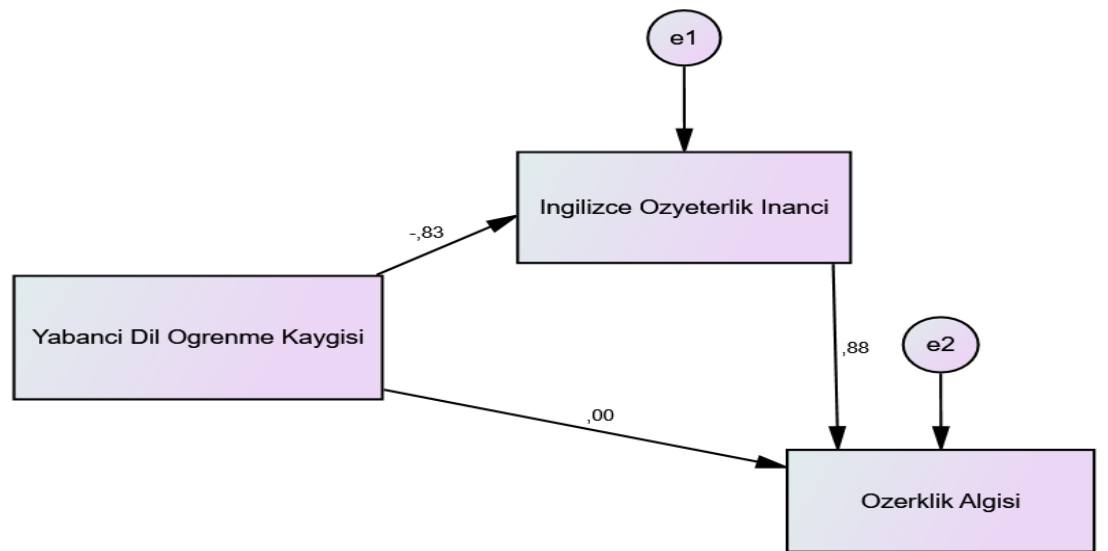

Şekil 1. İngilizce özyeterlik inançları aracı değişken olarak alındiğında yabancı dil öğrenme kaygısının özerkliğe etkisi (Standardize edilmiş tahminler)

Modele ilişkin uyum indeksleri; $\mathrm{X} 2 / \mathrm{sd}=4,18, \mathrm{RMSEA}=0,582$, AGFI $=$ $1,000, \mathrm{CFI}=1,000, \mathrm{NFI}=1,000$ ' dir. Bu değerlere göre modelin doğrulandığ 1 söylenemez. Modelde hesaplanan regresyon tahminlemeleri Tablo 4'te özetlenmiştir.

Tablo 4. Yabancı dil kaygı düzeyi ve İngilizce özyeterlik inancının özerklik üzerindeki etkileri

\begin{tabular}{|c|c|c|c|c|}
\hline Etkiler & Tahmin & $\begin{array}{l}\text { Standart } \\
\text { Hata }\end{array}$ & $\begin{array}{c}\text { Critical } \\
\text { Ratio } \\
\text { (C.R.) }\end{array}$ & p \\
\hline $\begin{array}{l}\text { Yabancı Dil Öğrenme Kay- } \\
\text { gisı } \rightarrow \text { İngilizce Özyeterlik İnanc1 }\end{array}$ & -37.169 & -0.515 & -0.014 & 0,000 \\
\hline $\begin{array}{l}\text { İngilizce Özyeterlik } \\
\text { İnancı } \rightarrow \text { Özerklik Algısı }\end{array}$ & 27.249 & 1.314 & 0.048 & 0,000 \\
\hline $\begin{array}{l}\text { Yabancı Dil Öğrenme Kay- } \\
\text { g1sı } \rightarrow \text { Özerklik Alg1sı }\end{array}$ & -0.028 & -0.001 & 0.030 & 0,977 \\
\hline
\end{tabular}

Tablo 4 ve şekil 1 incelendiğinde yabancı dil öğrenme kaygısının İngilizce özyeterlik inancı üzerinden dolaylı etkisinin negatif yönde korelasyon değeri (-0.83) pozitif yöne (0.88) dönmüştür. Baron ve Kenny'nin (1986, p. 1176) belirttiği üzere tam aracı değişken etkisi açıklayıcı değişken ile açıklanan değişken arasındaki ilişkiyi sıfıra indirme özelliği göstermektedir. Bu analizde aracı değişken ilişkiyi ters yöne çevirmiştir ancak 
elde edilen son ilişki $(\mathrm{r}=0.88)$ halen anlamlı düzeydedir. Aracı değişken dolaylı etkisi anlamlıdır $(\mathrm{p}<.05)$.

Tablo 4'te görülen doğrudan etkilere göre;

- Yabancı dil öğrenme kaygısı İngilizce özyeterlik inancının negatif yönde anlamlı bir açıklayıcısıdır ( $\mathrm{p}<.05)$.

- İngilizce özyeterlik inancı özerklik algısının pozitif yönde anlamlı bir açıklayıcısıdır $(\mathrm{p}<.05)$.

- Yabancı dil öğrenme kaygısı özerklik algısının anlamlı bir açıklayıc1sı değildir ( $\mathrm{p}>$.05).

\section{Tartışma ve Sonuç}

Araştırma sonuçlarına göre öğrencilerin İngilizce özyeterlik inancı ile özerklik algıları arasında pozitif yönde, yüksek düzeyde ve anlamlı bir ilişki olduğu belirlenmiştir. Buradan hareketle, öğrencilerin özyeterlilik inanç düzeyleri arttıkça özerklik algılarının da arttığı söylenebilir. Öğrencilerin özyeterlik düzeyleri ile öğrenen özerkliği arasında pozitif ilişki olduğu ilgili araştırma sonuçları da (Kanadlı ve Bağçeci, 2015; Orawiwatnakul ve Wichadee, 2017; Tilfarlioğlu ve Çiftci, 2011), bu araştırmanın bulgularını desteklemektedir. Yiğit ve Yıldırım (2018) tarafından yapılan araştırmada öğrencilerin dil eğitiminde aktiflik, kendi öğrenmeleri için sorumluluk olup hevesle etkinliklere katılma, öğrenmeye merak ve ilgi duyma, sosyal olma, güçlü ve zayıf yönlerini bilme, hedef sahibi olmalarının öğrenen özerkliği açısından önemli özellikler olduğu belirlenmiştir. Öğrenen özerkliğine sahip öğrenciler, kendi öğrenmelerini yönetebilmelerine inanan özgüvenli öğrenenlerdir (Wenden, 1991; Zhong, 2013). Ayrıca dil öğrenme sürecinde öğrenen özerkliği için, öğrenen bireyin kendine olan inancı etkili faktörler arasında yer alır (Carter, 1999). Öz yeterlilik algısı gelişmiş öğrenciler, öğrenme kapasitelerini bildikleri için kendi öğrenmelerini kontrol edebilirler (Bandura,1997). Özyeterlik, öğrenen özerkliğinin önkoşuludur (Schmenk, 2005).

Araştırma sonuçlarına göre öğrencilerin İngilizce özyeterlik inanc ile yabancı dil öğrenme kaygıları arasında negatif yönde, yüksek düzeyde ve anlamlı bir ilişki olduğu belirlenmiştir. Buradan hareketle, öğrencilerin özyeterlik inanç düzeyleri arttıkça yabancı dil öğrenme kaygısının azaldığı söylenebilir. Öğrencilerin İngilizce özyeterlik inancı ve yabancı dil 
öğrenme kaygısı arasındaki ilişkinin incelendiği birçok araştırmada da bu araştırmanın bulgularına benzer sonuçlara ulaşılmıştır (Anyadubalu, 2010; Aydın, 2016; Bensalem, 2018; Coşkun, 2017; Çimen, 2011; Demir, 2018; Ghonsooly ve Elahi, 2010; Kurt, 2016; Merç, 2015; Oğuz ve Baysal, 2015; Tucer ve Doğan, 2016). Yabancı dil öğreniminde düşük kaygı düzeyinin daha güçlü öz yeterlik inancına yol açtığı söylenebilir (Raoofi, Tan, ve Chan, 2012). Tuncer ve Doğan (2015) tarafından yapılan araştırmada ise bu araştırmanın bulgularının aksine özyeterlik ile yabancı dil dersine yönelik kaygı arasında yüksek düzeyde ve pozitif yönde ilişkiler olduğu belirlenmiştir. Diğer taraftan, Çubukçu (2008) tarafından yapılan araştırma ise bu araştırmanın bulgularının aksine dil öğrenme kaygısı ile öz yeterlik arasında anlamlı bir ilişki olmadığı belirlenmiştir.

Araştırma sonuçlarına göre, öğrencilerin özerklik algısı ile yabancı dil öğrenme kaygıları arasında negatif yönde, yüksek düzeyde ve anlamlı bir ilişki olduğu belirlenmiştir. Buradan hareketle, öğrencilerin özerklik alg1ları arttıkça yabancı dil öğrenme kaygısının azaldığı söylenebilir. İlgili alanyazını incelendiğinde bazı araştırmalarda da bu araştırmanın bulgularını destekler şekilde, öğrencilerinin özerklik algısı yabancı dil öğrenme kaygısı ile negatif yönde anlamlı ilişkiler olduğu belirlenmiştir (Kurt, 2016; Lui, 2012; Sanadgol ve Abdolmanafi-Rokni, 2015). Dil öğreniminde başarı için, öğrenen özerkliği etkili unsurların başında gelmektedir (Benson, 2007; Little, 2007). Başarılı ve daha az başarılı öğrenciler arasında öğrenci özerkliği algılarına göre bazı farklılıklar vardır. Başarılı öğrenciler öğrenen özerkliğine sahipken, daha az başarılı öğrenciler öğrenen özerkliğini edinme sürecindedirler (Mineishi, 2010).Yapılan araştırmalarda düşük kaygı düzeyine sahip öğrencilerin dil öğreniminde daha başarılı oldukları (Ghorbandordinejad ve Ahmadabad, 2016; Horwitz, 2001) ve daha fazla motivasyona sahip oldukları (Dickinson, 1995; Krashen, 1987; Sakai, Takagi, ve Chu, 2010) belirlenmiştir. Bu araştırmanın bulgularına dayalı olarak öğrencilerin kendi öğrenmelerinde daha fazla sorumluluk almalarına dayalı olan özerkliğin, yabancı dil öğrenme kaygısını azalttı̆̆ı gibi dil öğrenme başarısını olumlu yönde etkilediği söylenebilir.

Araştırma sonuçlarına göre öğrencilerin yabancı dil kaygı düzeyi arttıkça İngilizce özyeterlik inancı ve özerklik algısı düşmektedir. Buna karşın özerklik algısı arttıkça İngilizce özyeterlik inancı da artmaktadır. İlgili 
alanyazını incelendiğinde, öğrenen özerkliği, özyeterlik ve yabancı dil öğrenme kaygısı arasındaki ilişkiyi inceleyen başka araştırma olmayıp, araştırmanın ilk olduğu söylenebilir. Bu bakımdan belirtilen değişkenler arası ilişkilerin incelendiği araştırmalar yerine yakın olan çalışmalardan ayrılan ve benzer yönleri ortaya konabilir. Yabancı dil öğrenmede kaygı, dili etkili kullanmada ve dil öğrenmede başarı önünde engel olan en önemli faktörlerden biridir (Ganschow ve Sparks, 1996; Horwitz, 2001; Horwitz, Horwitz, ve Cope, 1986; Horwitz ve Young, 1991; Macintyre, 1995). Yabancı dil öğrenme kaygısının öğrencilerin dil öğrenme başarılarını (Amiri ve Ghonsooly, 2015: Chen ve Chang, 2009; Dordinejad ve Ahmadabad, 2014; Horwitz, 2001; Liu, 2006; MacIntyre ve Gardner, 1994) ve dil öğrenme motivasyonlarını olumsuz etkilediği (Gardner, Lalonde, Moorcroft, ve Evers 1987; Hashimoto, 2002; Liu, 2012; Tahernezhad, Behjat, ve Kargar, 2014) araştırma sonuçları ile ortaya konulmuştur. Ayrıca alanyazında öğrencilerin yabancı dil öğrenme kaygısı ve özyeterlik arasındaki negatif ilişkinin sonucuna bağlı olarak İngilizce özyeterlik inançlarının (Anyadubalu, 2010; Aydın, 2016; Bensalem, 2018; Coşkun, 2017; Çimen, 2011; Demir, 2018; Ghonsooly ve Elahi, 2010; Kurt, 2016; Merç, 2015; Oğuz ve Baysal, 2015; Tucer ve Doğan, 2016) ve özerklik algılarının azaldığ1 araştırmalarla (Kurt, 2016; Lui, 2012; Sanadgol ve Abdolmanafi-Rokni, 2015) ortaya konulmuş olup, elde edilen bulguların benzerlik gösterdiği söylenebilir.

Araştırma sonuçlarına gore öğrencilerin yabancı dil öğrenme kaygısı İngilizce özyeterlik inancının negatif yönde anlamlı bir tahmincisidir. Öğrencilerin yabancı dil öğrenme kaygısı İngilizce özyeterlik inancındaki değişimin anlamlı bir açıklayıcısıdır. Öğrencilerin yabancı dil öğrenme kaygisı yükselirse özyeterlik inancı azalma yönünde değişecektir. Birey dil öğrenmede yaşadığı kaygının devam etmesi, bireyin özyeterlik düzeyinin düşmesine ve öğrenme sürecinin başarısız olmasına ya da aksamasına yol açabilir.

Araştırma sonuçlarına göre öğrencilerin İngilizce özyeterlik inancı, özerklik algısının pozitif yönde anlamlı bir tahmincisidir. Öğrencilerin İngilizce özyeterlik inancı özerklikteki değişimin anlamlı bir açıklayıcısıdır. Öğrencilerin özyeterlik inancı yükselirse özerklik de artacaktır. Öğrenen özerkliğine sahip öğrenciler, kendi öğrenmelerini yönetebilme yeterlilikleri olan, sahip, otokontrol veözgüvene sahip öğrenenlerdir (Carter, 1999; 
Wenden, 1991; Zhong, 2013). Öz yeterlilik öğrenen özerkliğinin önkoşulu olup, özyeterlik algısı gelişmiş öğrenciler, öğrenen özerkliğini edinmiş öğrencilerdir (Bandura,1997; Schmenk, 2005). Özyeterlik ve öğrenen özerkliği, dil öğrenimi alanında akademik başarının en önemli iki belirleyicisi olduğu söylenebilir (Tilfarlioğlu ve Çiftci, 2011). Öğrenen özerkliği, dil öğrenmede motivasyonu ve bireyin özyeterliğini geliştirmektedir (Dörnyei, 1994; Xu ve Zhan, 2004). Araştırma sonuçlarına dayalı olarak, bireyin dil öğrenme sürecinde kendini tanıması ve bu doğrultuda hedefler koyması, dil edinme ile ilgili becerilerine olan inancı, dil öğrenmeye yönelik kişisel kararlar alması ve bu kararları uygulaması, kısaca öğrenme sorumluluğunu üstelenmesi sonucu hem motivasyonunu hem de özerklik becerilerini gelişeceği söylenebilir.

Araştırma sonuçlarına göre, öğrencilerin özyeterlik inancı öğrenen özerkliğini olumlu yönde etkilemekte, ayn şekilde öğrencilerin yabancı dil öğrenme kaygılarını azaltmaktadır. Yine artan kaygı hem özyeterlik inancını hem de öğrenen özerkliğini olumsuz olarak etkilemektedir. Araştırma bulgularına dayalı olarak, dil öğrenme sürecinde öğrencilerin kaygılarını azaltma, özyeterlik ve özerkliklerini desteklemek için; bireysel farklılıkları ve gelişimi temel alan öğrenme ortamları oluşturulması, öğretmenlerin öğrenci çalışmalarını destekleyen ve öğrencileri motive eden bir tutuma sahip olmaları, derslerde öğrenen merkezli öğrenme ortamları ve etkinliklere daha fazla yer verilmesi, yabancı dil kaygısı taşıyan öğrencilere psiko-sosyal destek sağlanması önerilmektedir. 
EXTENDED ABSTRACT

\title{
An Investigation of the Relationships Between English Language Learning Autonomy Perception, Anxiety Level and Self-Efficacy Perception among High School Students
}

\author{
Şenol Orakcı - Osman Aktan - Çetin Toraman \\ Aksaray University/Ministry of National Education/ Çanakkale Onsekizmart University
}

As a result of the developments in the field of information and technology in the century we live in, increasing mass media has led people and communities to have more communication and interaction. Foreign language plays an important role in ensuring interaction between individuals and societies (Demirel, 2014). Learning a foreign language enables students to recognize different cultures, to gain knowledge gained in different fields and to think in a universal way. At the same time, language learning provides opportunities for new jobs and understanding different thoughts (Bahar, 2011; İşcan, 2011). Learning a foreign language enables individuals to develop original solution strategies and creativity skills with a broad perspective to solve problems (Ghonsooly and Showqi, 2012; Hommel, Colzato, Fischer ve Christoffels, 2011; Pop, 2011). In addition, it takes the human being to a higher level than where it is located (Connor, 2016; König, 1989).

In foreign language courses, especially the level of anxiety, learner autonomy and self-efficacy perceptions can be important variables that may affect the performance of students in foreign language learning. It is believed that the study is important and it will contribute significantly to the literature, as there are no studies that analyze of the relationship between English language learning autonomy perception, anxiety level and selfefficacy perception of high school students. The study aims to examine the relationships between English language learning autonomy perception, anxiety level and self-efficacy perception of high school students and and 
whether Foreign Language Learning anxiety level and self-efficacy perception predict students' English language learning autonomy perception significantly.

\section{Method}

The level of explanations of high school students' English language learning anxiety level to learning autonomy perception by the variable of their self-efficacy perceptions in the research and the relationships between these variables were studied. The study is a correlational study. The sample group for the research comprised a total sum of 645 high school students from 5 different high schools in different districts in Ankara province in Turkey. Sample of the research was chosen utilizing purposive and easily accessible sampling. In the study, "Self-efficacy Scale", "Autonomy Perception Scale" and "Foreign Language Learning Anxiety Scale" were employed as tools of data collection.

\section{Results}

Centered on the findings of the study, it was found that there was a high level, positive and significant relationship between self-efficacy and autonomy perceptions whereas a high level and negative relationship was found between self-efficacy and foreign language learning anxiety anxiety and a high level, negative relationship between foreign language learning anxiety and autonomy perception in English learning. In addition, it was determined that foreign language learning anxiety was a significant negative predictor of self-efficacy whereas it was a significant positive predictor of autonomy perception. It was also determined that foreign language learning anxiety was not a significant predictor of autonomy perception.

\section{Discussion and Conclusion}

Students with learner autonomy are self-confident learners who believe that they can manage their own learning (Wenden, 1991; Zhong, 2013). Moreover, the self-belief of the learner for the learner autonomy in the lan- 
guage learning process is one of the influential factors (Carter, 1999). Students with self-efficacy perception can control their own learning because they know their learning capacities (Bandura, 1997). Self-efficacy is a prerequisite for learner autonomy (Schmenk, 2005). It is possible to say that self-efficacy and learner autonomy are the two most important determinants of academic achievement in language learning (Tilfarlioğlu and Çiftci, 2011).

Anxiety in foreign language learning is one of the most important factors that impedes language success and prevents language from being used effectively. Lots of studies carried out in the literature revealed that foreign language learning anxiety had a bad and negative effect on students' language learning achievements(Amiri ve Ghonsooly, 2015: Chen ve Chang, 2009;Dordinejad ve Ahmadabad, 2014; Horwitz, 2001; Liu, 2006; MacIntyre and Gardner, 1994) and language learning motivations Gardner, Lalonde, Moorcroft ve Evers 1987; Hashimoto, 2002; Liu, 2012; Tahernezhad, Behjat ve Kargar, 2014).

Students' anxiety about learning a foreign language is a significant explanation for the change in the belief of English self-efficacy. If students' anxiety about learning foreign languages increases, their self-efficacy belief will decrease. The continuation of the anxiety in language learning may lead to a decrease in the level of self-efficacy or failure of the learning process.

Centered on the results of the research, it is possible to say that if the individual recognizes himself/herself in the process of language learning and has a belief in his/her skills related to language acquisition, if he/she takes personal decisions about language learning and applies these decisions, he/she will develop both his/her motivation and autonomy skills. With regar to the findings of the study, creating learning environments based on individual differences and development, teachers' having a motivating attitude to students, giving more importance to learner-centered learning environments and activities, in additioon to providing psychosocial support with students who has foreign language anxiety are recommended. 


\section{Kaynakça}

Amiri, M., ve Ghonsooly, B. (2015). The relationship between English learning anxiety and the students' achievement on examinations. Journal of Language Teaching and Research, 6 (4), 855-865. http://dx.doi.org/10.17507/jltr.0604.20.

Anaydubalu, C. C. (2010). Self-efficacy, anxiety, and performance in the English language among middle-school students in English language program in SatriSuriyothai School, Bangkok. International Journal of Human and Social Sciences, 5(3), 193-198.

Aydın, Y.(2016). Lise öğrencilerinin yabancı dil kaygısının farklı değişkenler açısindan incelenmesi. Yayımlanmamış Yüksek Lisans Tezi.Ahi Evran Üniversitesi Sosyal Bilimler Enstitüsü, Kırşehir.

Baş, G. (2013). Yabancı dil öğrenme kaygısı ölçeği: Geçerlik ve güvenirlik çalışması. Türkiye Sosyal Araştırmalar Dergisi, 172(172), 49-68

Bahar, M. (2011). Türkiye'de yabancı dil öğrenimi ile ilgili sorunlar. Kariyer Penceresi, 3, 17.

Bailey, K. M. (1983). Competitiveness and anxiety in adult second language learning: Looking at and through the diary studies. In H. W. Seliger ve M. H. Long (Eds.), Classroom oriented research in second language acquisition. Rowley, MA: Newbury.

Bandura, A. (1997). Self-efficacy: The exercise of control. New York: W.H. Freemanand Company.

Bayat, Ö. (2007). Yabancı dil olarak İngilizce öğrenenlerde özerklik algısı, okuduğunu anlama başarısı ve sını içi davranışlar arasındaki ilişkiler. Doktora Tezi. Dokuz Eylül Üniversitesi, Eğitim Bilimleri Enstitüsü, İzmir.

Bensalem, E.(2018). Foreign language anxiety of EFL students: examining the effect of self-efficacy, self- perceived proficiency and sociobiographical variables. Arab World English Journal (AWEJ), 9 (2), 3855.DOI: https://dx.doi.org/10.24093/awej/vol9no2.3.

Benson, P. ve Voller, P. (1997). Autonomy and Independence in Language Learning. London: Longman.

Benson, P. (2006). Autonomy in language teaching and learning. Language Teaching, 40, 21-40. 
Blumenthal, L. F. (2014). Self-Efficacy in Low-Level English Language Learners. . (Unpublished MA thesis). Portland State University, Portland, USA.

Brown, H. D. (2000). Principles of language learning and teaching. New York, NY: Addison Wesley Longman.

Camilleri, G.(1997). Learner Autonomy-The Teachers Views. 15 Ocak 2019 tarihinde http://archive.ecml.at/documents/pubCamilleriG_E.pdf adresinden erişildi.

Carter, B.A. (1999). Begin with beliefs: Exploring the relationship between beliefs and learner autonomy among advanced students. Texas $P a-$ pers in Foreign Language Education, 4 (1), 1-20.

Chen, I. J., ve C. C. Chang. (2009). Cognitive load theory: An empirical study of anxiety and task performance in language learning. Electronic Journal of Research in Educational Psychology, 7(2), 729-746.

Christensen, L. B., Johnson, R. B., ve Turner, L. A. (2015). Research methods, design, and analysis (12th ed.). (Aypay, A., Çev. Edt.) Boston: Pearson. (Orijinal çalışmanın basım tarihi 2014).

Connor S. (2016). Learning second language can delay ageing of the brain, say scientists. Availableonline at: http://www.independent.co.uk/news/science/learning-second-language-can-delayageing-of-the-brain-say-scientists-a6873796.html [Accessed on November 18, 2018].

Cook, V. (2008). Second language learning and language teaching. London: Edward Arnold.

Çakıcı, D. (2015). Autonomy in Language Teaching Process. İnönü University Journal of the Faculty of Education. 16 (1), 31-42.

Çimen, S. (2011). Eğitim fakültesi öğrencilerinin İngilizceye yönelik tutum, İngilizce kaygısı ve öz yeterlik düzeylerinin incelenmesi. Yayımlanmamış Yüksek Lisans Tezi. Zonguldak Karaelmas Üniversitesi Sosyal Bilimler Enstitüsü, Zonguldak.

Çoşkun, G.(2017). Üniversite öğrencilerinin İngilizce dersine ilişkin kaygıları, tutumları, özyeterlik inançları ve dil öğrenme stratejilerinin incelenmesi. Yayımlanmamış Yüksek Lisans Tezi. Atatürk Üniversitesi Eğitim Bilimleri Enstitüsü, Erzurum 
Çubukcu, F. (2008). A study on the correlation between self efficacy and foreign language learning anxiety. Journal of Theory and Practice in Education, 4 (1), 148-158.

Demir, B. (2018).Yabancı dil hazırlık okulunda özyeterlikinancı ve yabancı dil öğrenme kaygısı arasındaki ilişki. Yayımlanmamış Yüksek Lisans Tezi. Çă̆ Üniversitesi Sosyal Bilimler Enstitüsü, Mersin.

Demirel, Ö. (2014.). Yabancı Dil öğretimi: Dil pasaportu, dil biyografisi, dil dosyası (14.Baskı). Ankara: Pegem Akademi.

Dickinson, L. (1987). Self-instruction in language learning. Cambridge: Cambridge University.

Dickinson, L. (1995). Autonomy and motivation. System, 23 (2), 165.

Dörnyei, Z. (2005) The psychology of the language learner: Individual differences in second language acquisition. Mahwah, NJ: Lawrence Erlbaum.

Dordinejad, F. G. ve Ahmadabad, R. M. (2014). Examination of the relationship between autonomy and English achievement as mediated by foreign language classroom anxiety. Journal of Psycholinguist Research, 45(3). 739-752. doi:10.1007/s10936-015-9371-5.

Dornyei, Z. (1994). Motivation and motivating in the foreign language classroom. Modern Language Journal, 78 (3), 273-284. doi:10.2307/330107.

Dörnyei, Z. (2012). The psychology of second language acquisition. Oxford University, UK.

Fraenkel, J.R., Wallen, N.E. ve Hyun, H.H. (2012). How to design and evaluate research in education. USA: McGraw-Hill Companies Inc.

Gardner, R. C., Lalonde, R. N., Moorcroft, R. ve Evers, F. T. (1987). Second language attrition: The role of motivation and use. Journal of Language and Social Psychology, 6, 29-47.

Gass, S. M. ve Selinker, L. (2008). Second language acquisition. USA: Routledge.

Ghonsooly, B. ve Showqi, S. (2012). The effects of foreign language learning on creativity. English Language Teaching, 5 (4), 161-167.

Ganschow, L. ve Sparks, R. L. (1996). Anxiety about foreign language learning among high school women. The Modern Language Journal, 80, 199-212. doi: 10.1037/0022-0663.89.3.549 
Ghonsooly, B. ve Elahi, M. (2010). Learners' self-efficacy in reading and its relation to foreign language reading anxiety and reading achievement. Journal of English Language Teachingand Learning, 53 (127), 4567.

Green, S. B. ve Salkind, N. J. (2008). Using SPSS for Windows and Macintoshanalyzing and understanding data. USA: PearsonPrentice Hal.

Gregersen, T.S. ve Horwitz, E.K. (2002). Language learning and perfectionism: Anxious and non-anxious language learners" reactions to their own oral performance. The Modern Language Journal, 86 (3), 562-570.

Gremmo, M.J. ve Riley, P. (1995). Autonomy, self-directionand self-access in language teaching and learning: the history of an idea. System, 23 (2), 151-64.

Hancı, Y. B. ve Bümen, N. T. (2012). İngilizce ile ilgili özyeterlik inanc1 ölçeğinin geliştirilmesi. Kastamonu Eğitim Dergisi, 20 (1), 97-110.

Holec, H. (1981). Autonomy in Foreign Language Learning. Oxford: OUP.

Holec, H. (1985). On autonomy: Some elementary concepts. In P. Riley (Ed.) Discourse and learning (pp. 173-190). London: Longman.

Hommel, B.,Colzato, L., S., Fischer, R. ve Christoffels I., K. (2011). Bilingualism and creativity: benefits in convergent thinking come with losses in divergent thinking. Frontiers in psychology, 2, 273. http://dx.doi.org/10.3389/fpsyg.2011.00273

Horwitz, E. K.,Horwitz, M. B., ve Cope, J. (1986). Foreign language classroom anxiety. The Modern Language Journal, 70, 125-132. doi:10.1111/j.1540-4781.

Horwitz, E.K ve Young, D.J. (1991) Language anxiety: From theory ve Research To classroom implications. University of Tennessee: Pearson.

Horwitz, E.K. (2001). Language anxiety and achievement. Annual Review of Applied Linguistics, 21, 112-126.

Hashimoto, Y. (2002). Motivation and willingness to communicate as predictors of L2. Use: The Japanese ESL context. Second Language Studies, 20 (2), 29-70.

İşcan, A. (2011). Türkçe'nin yabancı dil olarak önemi. Uluslararası Avrasya Sosyal Bilimler Dergisi, 4, 29-36. 
Kalaycı, Ş. (2005). SPSS uygulamalı çok değişkenli istatistik teknikleri. Ankara: Asil.

Kanadlı, S. ve Bağçeci, B. (2015). Öğrencilerin İngilizce öz-yeterlilik inançlarının algılanan özerklik desteği açısından incelenmesi. Mustafa Kemal Üniversitesi Sosyal Bilimler Enstitüsü Dergisi, 12 (30), 98-112.

Khojasteh, Z. ve Pishkar, K. (2015). The Relationship between Iranian EFL Learners' Sensory Learning Style and Their Autonomy Level. Journal of Applied Linguistics and Language Research, 2 (6), 179-189.

Kline, R. B. (2011). Principles and practice of structural equation modeling. USA: The Guilford.

König, W. (1989). Türkiye'deki yabancı dil öğretimi sorunları, dışarıdan bir bakış. Hacettepe Üniversitesi Eğitim Fakültesi Dergisi, 4, 167-172.

Krashen, S. D. (1987). Principles and practice in second language acquisition. Prentice-Hall International.

Kupeckova, L. (2010). Game-like activities.Bachelor thesis from Masaryk University Faculty of Education Department of English Language and Literature.Brno, Czech Republic. Retrieved: https://is.muni.cz/th/zlhav/Game like activities FINAL.pdf. [Accessed on March 18, 2019].

Kurt, E. (2016). Lise öğrencilerinin İngilizce öğrenme özerklik algılarının duyuşsal faktörlerce yordanma durumu. Yüksek Lisans Tezi. Eskişehir Osmangazi Üniversitesi, Eğitim Bilimleri Enstitüsü, Eskişehir.

Lier, V. L. (1996). Interaction in the Language Curriculum. Awareness, Autonomy and Authenticity. USA: Longman.

Little, D. (1999). Developing learner autonomy in the foreign language classroom: a social-interactive view of learning and three fundamental pedagogical principles. Revista Canaria de Estudios Ingleses, $38,77-88$.

Little, D. (2000). Learner autonomy and human interdependence: some theoretical and practical consequences of a social-interactive view of cognition, learning and language. In B. Sinclair, I. McGrathand T. Lamb (eds). Learner Autonomy, Teacher Autonomy: Future Directions, 15-23. Harlow: Longman/Pearson Education.

Little, D. (2007). Language learner autonomy: Some fundamental considerations revisited. Innovation in Language Learning and Teaching, 1 (1), 14-29. 
Liu, M. (2006). Anxiety in Chinese EFL students at different proficiency levels. System, 34, 301-316. http://dx.doi.org/10.1016/j.system.2006.04.004.

Liu, H. J. (2012). Understanding EFL under graduate anxiety in relation to motivation, autonomy, and language proficiency. Electronic Journal of Foreign Language Teaching, 9 (1), 123-139.

Liu, H. (2015). Learner autonomy: The role of motivation in foreign language learning. Journal of Language Teaching and Research, 6 (6), 11651174. doi:10.17507/jltr.0606.02.

MacIntyre, P. D. ve Gardner, R. C. (1989) Anxiety and Second Language Learning: Toward a Theoretical Clarification. Language Learning, 39, 251-275.

MacIntyre, P. D. ve Gardner, R. C. (1994). The subtle effects of language anxiety on cognitive processing in the second language. Language Learning 44, (2), 83-305

Macintyre, P. D. (1995). How does anxiety affect second language learning? A reply to Sparks and Ganschow. The Modern Language Journal, 79, 91-99. doi: 10.1177/1463499603003002002.

Mede, E.,İnceçay, G. ve İnceçay, V. (2013). Fostering Learner Autonomy through Extensive Reading: The Case of Oral Book Reports. ELT Research Journal, 2 (1), 16-25.

Merç, A. (2015). Foreign Language Teaching Anxiety and Self-Efficacy Beliefs of Turkish Pre- Servie EFL Teachers. The International Journal of Research in Teacher Education, 6 (3), 40-58.

Mineishi, M. (2010). East Asian EFL Learners' Autonomous Learning, Lerner Perception on Autonomy and Portfolio Development: In the Case of Educational Contexts in Japan. International Journal of Artsand Sciences, 3 (17), 234-241.

Nunan, D. (2004). Nine Steps to Learner Autonomy [online]. In Olofsson, M. (red.), Symposium 2003: Arena andraspråk. Stockholm:HLS Förlag. $\quad$ http://www.andrasprak.su.se/polopoly fs/1.84007.1333707257!/menu/standard/file/2003 $11 \mathrm{Nu}-$ nan eng.pdf. [Accessed on March 18, 2019]

Oğuz, A. ve Baysal, E. (2015). Ortaöğretim öğrencilerinin İngilizce öğrenme kaygıları ile İngilizce öz yeterlik inançlarının incelenmesi. Ĕ̆itim ve Öğretim Araştırmaları Dergisi, 4(3), 14, 107-117. 
Orakc1, Ş. (2017). Öğrenen özerkliğine dayanan öğretim etkinliklerinin 6. sınıf öğrencilerinin ingilizce başarllarına, tutumlarma, öğrenen özerkliklerine ve kahıcı öğrenmelerine etkisi. Yayımlanmamış Doktora Tezi. Gazi Üniversitesi, Eğitim Bilimleri Enstitüsü, Ankara.

Orakc1, Ş., ve Gelişli, Y. (2017). Learner autonomy scale: A scale development study. Malaysian Online Journal of Educational Sciences, 5(4), 24-35.

Orakcı, Ş. (2018). İngilizce dinleme kaygısı ölçeği'nin geçerlik ve güvenirlik çalışması. Asya Öğretim Dergisi, 6 (1), 40-51.

Orawiwatnakul, W., ve Wichadee, S. (2017). An investigation of under graduate students' beliefs about autonomous language learning. International Journal of Instruction, 10 (1), 117-132.

Özdamar, K. (2013). Paket programlar ile istatistiksel veri analizi. Eskişehir: Nisan Kitabevi.

Roberts, M., ve Meyer, A. (2012). Individual differences in second language learning: introduction, Language Learning, 62 (2), 1-4.

Raoofi, S., Tan, B. H. ve Chen, S. H. (2012). Self-efficacy in second/foreign language learning Contexts. English Language Teaching, 5(11), 6073. http://dx.doi.org/10.5539/elt.v5n11p60.

Sakai, S.,Takagi, A. ve Chu, M.-P. (2010). Promoting learner autonomy: Student perceptions of responsibilities in a language classroom in East Asia. Educational Perspectives, 43, 12-27.

Sanadgol, F. ve Abdolmanafi-Rokni, S. J. (2015). Anxiety, Motivation and Autonomy in Iranian High School Students: A Quantitative Study. Advances in Language and Literary Studies, 6 (1), 143-149. doi: 10.7575/aiac.alls.v.6n.1p.143.

Scharle, A. ve Szabo, A. (2000). Learner autonomy: A guide to developing learner responsibility. Cambridge: Cambridge University.

Schmenk, B. (2005). Globalizing learner autonomy. TESOL Quarterly, 31(1), 107-118.

Schunk, D. H. (2003). Self-efficacy for reading and writing: Influence of modeling, goal setting, and self-evaluation. Reading and Writing Quarterly, 19, 159-172.

Skehan, P. (1989). Individual differences in second-language learning. London: Edward Arnold. 
Şanal, F. (2016a). Learner Autonomy Issue. Abant İzet Baysal Üniversitesi Eğitim Fakültesi Dergisi, 16 (3), 1026-1034.

Şenol, Ş. (2012). Araştırma ve örnekleme yöntemleri. Ankara: Nobel Akademik.

Şimşek, Ö. F. (2007). Yapısal eşitlik modellemesine giriş: Temel ilkeler ve LISREL uygulamaları. İstanbul: Ekinoks.

STATA. (2013). STATA multi variate statistics reference manual, release 13. USA: A STATA.

Sümer, N. (2000). Yapısal eşitlik modelleri: Temel kavramlar ve örnek uygulamalar. Türk Psikoloji Yazıları, 3(6), 49-73.

Tahernezhad, E.,Behjat, F. ve Kargar, A. (2014). The Relationship between Language Learning Anxiety and Language Learning Motivation among Iranian Intermediate EFL Learners. International Journal of Language and Linguistics, 2 (6-1), 35-48. doi: 10.11648/j.ijll.s.2014020601.16

Tilfarlioğlu, F. T. ve Çiftci, F. S. (2011). Supporting self-efficacy and learner autonomy in relation to academic success in EFL classrooms:A case study. Theory and Practice in Language Studies, 1(10), 1284-1294. http://dx.doi.org/10.4304/tpls.1.10.1284-1294.

Tsai, C.C. (2013). The Impact of foreign language anxiety, test anxiety, and self-efficacy among senior high school students in Taiwan. International Journal of English Language and Linguistics Research, 1 (3), 117.

Tuncer, M. ve Dogan, Y (2016). Relationships among Foreign Language Anxiety, Academic Self-Efficacy Beliefs, and Metacognitive Awareness: A Structural Equation Modelling. International Journal of Learning and Development, 6 (2),31-41.

Tuncer, M. ve Dogan, Y. (2015). Hazırlık Sınıfı Öğrencilerinin Yabancı Dil Ders Kaygıları ve Akademik Öz-yeterlikleri Arasındaki İlişki. Dil ve Edebiyat Eğitimi Dergisi, 14, 153-167.

Wenden, A. (1991). Learner Strategies for Learner Autonomy: Planning and Implementing Learner Training for Language Learners. UK: PrenticeHall.

Yanar, B. H. ve Bümen, N. T. (2012). İngilizce ile ilgili özyeterlik inancı ölçeğinin geliştirilmesi. Kastamonu Ĕ̆̆itim Dergisi, 20 (1), 97-110. 
Yiğit, G. ve Yıldırım, O.(2018). Perceptions of ELT students related to learner autonomy in language learning. International Journal of Higher Education, 7 (4),76-89. doi:10.5430/ijhe.v7n4p76.

Zhong, Q. (2013). Learner Beliefs and Learner Autonomy: A Case Study of Two Chinese Migrant Learners in New Zealand, In May, S. (Ed.) (2013). LED2011: Refereed conference proceedings of the 3rd International Conference on Language, Education and Diversity. Auckland, New Zealand: The University of Auckland.

\section{Kaynakça Bilgisi / Citation Information}

Orakc1, Ş., Aktan, O. ve Toraman, Ç. (2019). Lise öğrencilerinin İngilizce özerklik algısı, kaygısı ve özyeterlik inancı arasındaki ilişkinin incelenmesi. OPUS-Uluslararası Toplum Araştırmaları Dergisi , 11(18), 424-450. DOI: 10.26466/opus.537460 